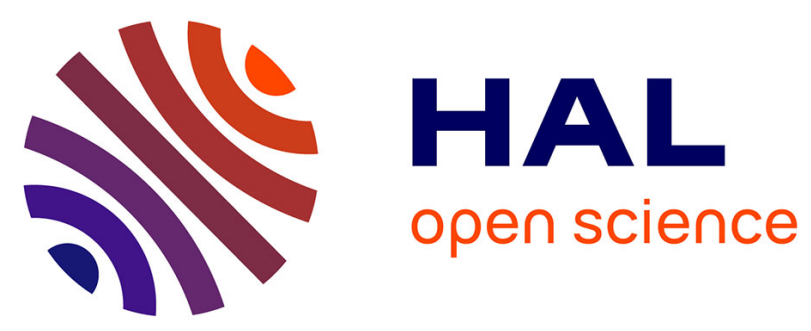

\title{
Investigating in utero fetal death outcome of internal medicine consultation
}

Nicolas Belhomme, Marine Le Noir de Carlan, Alain Lescoat, Thomas Le Gallou, Florence Rouget, Philippe Loget, Patrick Jego

\section{To cite this version:}

Nicolas Belhomme, Marine Le Noir de Carlan, Alain Lescoat, Thomas Le Gallou, Florence Rouget, et al.. Investigating in utero fetal death outcome of internal medicine consultation. International Journal of Rheumatic Diseases, 2018, 21 (2), pp.381-386. 10.1111/1756-185X.13116 . hal-01730383

\section{HAL Id: hal-01730383}

\section{https://hal-univ-rennes1.archives-ouvertes.fr/hal-01730383}

Submitted on 24 Apr 2018

HAL is a multi-disciplinary open access archive for the deposit and dissemination of scientific research documents, whether they are published or not. The documents may come from teaching and research institutions in France or abroad, or from public or private research centers.
L'archive ouverte pluridisciplinaire HAL, est destinée au dépôt et à la diffusion de documents scientifiques de niveau recherche, publiés ou non, émanant des établissements d'enseignement et de recherche français ou étrangers, des laboratoires publics ou privés. 


\section{Investigating In Utero Fetal Death: outcome of the internal medicine consultation.}

\begin{tabular}{|r|l|}
\hline Journal: & \multicolumn{1}{|c|}{ International Journal of Rheumatic Diseases } \\
\hline Manuscript ID & Draft \\
\hline Manuscript Type: & Original Article \\
\hline Date Submitted by the Author: & n/a \\
\hline Complete List of Authors: & $\begin{array}{l}\text { BELHOMME, Nicolas; Centre Hospitalier Universitaire de Rennes, Médecine } \\
\text { Interne } \\
\text { Le Noir De Carlan, Marine; Centre Hospitalier Universitaire de Rennes, } \\
\text { Médecine Interne } \\
\text { Lescoat, Alain; Centre Hospitalier Universitaire de Rennes, Médecine } \\
\text { Interne; INSERM, IRSET, UMR 1085, Rennes, France } \\
\text { Le Gallou, Thomas; Centre Hospitalier Universitaire de Rennes, Médecine } \\
\text { Interne } \\
\text { Rouget, Florence; Centre Hospitalier Universitaire de Rennes, Pédiatrie; } \\
\text { INSERM, IRSET, UMR 1085, Rennes, France; Réseau Périnatal 35 } \\
\text { Loget, Philippe; Centre Hospitalier Universitaire de Rennes, } \\
\text { Anatomopathologie } \\
\text { Jego, Patrick; Centre Hospitalier Universitaire de Rennes, Médecine } \\
\text { Interne; INSERM, IRSET, UMR 1085, Rennes, France }\end{array}$ \\
\hline Keywords: & $\begin{array}{l}\text { Clinical aspects < Anti-phospholipid antibody syndrome, Drug treatment < } \\
\text { Anti-phospholipid antibody syndrome, Epidemiology < Anti-phospholipid } \\
\text { antibody syndrome }\end{array}$ \\
\hline
\end{tabular}


1 Title page

2 Investigating In Utero Fetal Death: outcome of the internal medicine consultation.

3 Nicolas Belhomme ${ }^{\theta 1}$ M.D., Marine Le Noir de Carlan $^{1}$ M.D., Alain Lescoat ${ }^{2}$ M.D., Tomas Le

4 Gallou ${ }^{1}$ M.D., Florence Rouget ${ }^{3}$ M.D., Philippe Loget ${ }^{4}$ M.D., Patrick Jego ${ }^{2}$ M.D., Ph.D.

$5 \quad{ }^{\theta}$ Corresponding author:

6 Nicolas Belhomme

7 Department of Internal Medicine, CHU Rennes; University of Rennes 1

8 2, rue Henri Le Guilloux, 35000 Rennes, France

9 Email: nicolas.belhomme@chu-rennes.fr. Tel:+332 99284321

\section{Affiliations:}

$11{ }^{1}$ Department of Internal Medicine, CHU Rennes, Rennes, France; University of Rennes 1, 12 France.

13 2Department of Internal Medicine, CHU Rennes, Rennes, France; INSERM, IRSET, UMR 14 1085, Rennes, France

$15{ }^{3}$ INSERM, IRSET, UMR 1085, Rennes, France; Department of Pediatrics, CHU Rennes, 16 Rennes, France.

$17{ }^{4}$ Department of pathology, CHU Rennes, Rennes, France.

18 Running title: Placenta related fetal death.

19 Nicolas Belhomme and Marine Le Noir de Carlan wrote the manuscript; Alain Lescoat and 20 Florence Rouget performed the statistical analyzis, Philippe Loget provided the pictures and 21 contributed to the pathological data record, Thomas Le Gallou and Patrick Jego supervised 22 and proofread the manuscript.

23 Acknowledgements: the authors are indebted to Mrs Gaëlle Belhomme for her help in 24 writing the manuscript. 


\section{ABSTRACT}

27 Aim: The objectives were to determine the frequency of in utero fetal death (IUFD) related to 28 placental disorders and to assess the frequency of antiphospholipid antibodies syndrome 29 (APS) among women referred to the internal medicine department.

30 Methodology: A retrospective clinical study conducted in Rennes University Hospital, 31 France.

32 Results: From January 2007 to December 2014, 53 women who presented an IUFD at 14 33 weeks or more of gestational age were included. The main cause for each IUFD was 34 determined by expert agreement. Primary outcome was the prevalence of IUFD related to 35 placental disorders. Secondary outcomes included the frequency of antiphospholipid 36 antibodies syndrome (APS) among patients with IUFD of placental origin and the 37 pathological and clinical features associated to APS. IUFD resulted from placental disorders 38 in $36 / 53(68 \%)$ patients, and remained unexplained in 11 cases (20.8\%). Among the 36 patients with placental disorders, APS was diagnosed in $5(13.9 \%)$ cases, and $4(11.1 \%)$ patients were considered as having "non-criteria" APS. History of thrombosis $(p=0.001)$ and placental infarcts $(p=0.047)$ were significantly associated to APS.

Conclusion: Placental disorders were the major cause for IUFD in patients who were referred to internal medicine specialists. Importantly, APS was seldom found in patients with placental disorders. Venous thromboembolism history and placental infarcts were both significantly associated to APS. Further studies are needed in order to deepen our understanding of the physiopathology of placental disorders and its underlying causes

47 among non-APS women, and to determine the best treatment regimen for future 48 pregnancies.

49 Abbreviations: IUFD= In Utero Fetal Death. APS= Antiphospholipid Antibodies Syndrome. 
Keywords: in utero fetal death, stillbirth, internal medicine, placental pathology,

51 antiphospholipid antibodies syndrome, placental vascular disorders

52 Tweetable abstract: a study analyzing the prevalence of fetal death related to placental 53 disorders in internal medicine.

INTRODUCTION

56 There is currently no international consensus on the gestational age threshold which defines 57 In Utero Fetal Death (IUFD). The French National College of Gynecologists and 58 Obstetricians (CNGOF) defines IUFD as a spontaneous cessation of fetal cardiac activity 59 occurring before or during labor, after 14 weeks of amenorrhea ${ }^{1}$, whereas the threshold of 60 either 22 or 28 weeks or more is commonly used in many countries. ${ }^{23}$

61 Bukowski et al ${ }^{4}$ showed that obstetric complications, placental disease, genetic abnormality 62 and infections, were involved in respectively $29 \%, 26 \%, 13 \%$ and $13 \%$ of IUFD, then 63 followed by cord abnormalities (10.4\%), hypertensive disorders (9.2\%), and maternal 64 complications (7.8\%). IUFD were considered idiopathic in $24 \%$ of cases.

65 The objectives of IUFD investigations are to identify the cause, to prepare for future 66 pregnancies, and to detect a maternal pathology requiring specific care, such as 67 antiphospholipid antibodies syndrome (APS). ${ }^{1}$

68 APS diagnosis requires the presence of clinical and biological criteria meeting the Sydney 69 classification criteria. ${ }^{5}$ However, many patients, while fulfilling the clinical criteria, cannot be 70 classified as having APS either because of low titers or non-persistent positivity of 71 conventional antibodies, or because of the detection of other antibodies that have currently 72 not been validated (eg anti-prothrombin...): in those cases, the appellation of "non-criteria" 73 APS is sometimes used. ${ }^{67}$

74 


\section{Study objectives}

76 The objectives of our study were to bring to light the internist's role in the diagnosis of IUFD 77 by 1) analyzing the final etiologies diagnosed, on which depend the treatments that will be 78 proposed for future pregnancies 2) evaluating the prevalence of IUFD consecutive to 79 placental vascular disorders 3) assessing the prevalence of APS among these patients and 80 comparing their clinical and pathological features to non-APS patients, in order to find out 81 relevant factors that support APS testing.

\section{METHODS}

84 85 86

All women who consulted in the internal medicine department of Rennes University hospital, a French tertiary care center, after IUFD (defined as death at 14 weeks of gestation or later according to the CNGOF) were retrospectively included between January, $1^{\text {st }} 2007$ and December, $31^{\text {st }} 2014$. All cases of IUFD were reviewed by four specialists (a pediatrician, a pathologist specialised in foetopathology, an obstetrician and an internist) and the main cause of death was determined through consensual agreement.

According to the Amsterdam Placental Workshop Group Consensus Statement ${ }^{8}$, the following histological features were recorded from the pathological records: placental infarcts, retroplacental hematoma, hypotrophia, decidual arteriopathy, fetal vascular malperfusion, thrombosis, villitis, intervillitis, and cord abnormalities. IUFD were classified as placentarelated if the lesions observed were deemed sufficient to lead to fetal death.

APS testing results were recorded for all patients, and obstetrical APS was diagnosed according to Sydney criteria. Clinical and pathological characteristics of patients with APS, "non-criteria" APS and no APS were compared. Patients with APS were classified in the "maternal cause" category according to the CODAC classification[9], and they were also considered as placenta-related IUFD if their placentas exhibited significant lesions. 


\section{Statistical methods}

101 Categorical variables associations were analyzed by conducting a Chi square or Fisher exact 102 test. Quantitative data was analyzed by conducting student or Mann and Whitney U test. We 103 performed all tests with a significance level of $\mathrm{P}<0.05$. Statistical analyzis was performed 104 using SPSS 20.0 software.

105 This study was approved by the ethics committee of Rennes University Hospital.

106

107 RESULTS

\section{Patients' characteristics}

10953 patients consulted in internal medicine for IUFD, all of whom were referred by their 110 obstetrician. 22 patients (42\%) were primigravida, 5 patients $(9 \%)$ had a history of IUFD, 9 111 patients (17\%) had a history of miscarriage, 2 patients had an antecedent of preeclampsia, 2 112 patients an antecedent of HELLP syndrome. A history of severe fetal growth restriction $(<5$ 113 percentile) was mentioned in two cases. One patient suffered from chronic hypertension, no 114 patients had diabetes mellitus and none had renal disease. 9 patients (13\%) were overweight 115 or obese. Three patients were known to have APS, revealed in all cases by venous thrombo116 embolism (VTE). APS was considered as primary in all cases as none of our patient had 117 associated connective tissue disease. The patients' mean age at the time of IUFD was of 30 118 +/- 4.5 years (extremes: 19-42). The mean term was 29.2 weeks of amenorrhea +/- 7.9 119 (extremes 15-40). There were no multiple pregnancies. Distribution of IUFD according to 120 gestational age is shown in Figure 1.

121 At the time of IUFD, $7 / 53(13 \%)$ patients were receiving anticoagulant therapy or antiplatelet 122 agents: 4 patients were treated with low dose aspirin (LDA), because of previous fetal loss in 1233 cases, and of severe fetal growth restriction in one case. The three patients with known 124 APS were receiving LDA combined with low-molecular-weight heparin (LMWH). 


\section{Biology}

126 Conventional APL (LA, aCL and $\beta 2-\mathrm{GPI})$ were tested in $49 / 53$ patients $(90 \%)$, and were 127 positive in $9(17 \%)$ cases.

128 Among the 9 APL positive patients, 8 underwent repeat testing 12 weeks later. Among them, 1295 still tested positive: they were classified as having definite APS. The four other patients 130 presented "non-criteria" APS: one of them was tested positive for LA without confirmation 12 131 weeks apart and presented low titers aCL, the 3 others were negative for conventional APL, 132 but tested positive for anti-prothrombin antibodies.

\section{Pathological findings}

134 A placental histological analyzis was performed in 49/53 cases (92\%). Anomalies were found 135 in $40 / 49(81 \%)$ of the placentas.

136 Vascular disorders were noted in $33 / 49(73 \%)$ placentas. Retroplacental hematoma was 137 found in 10 cases, infarcts in 19 cases. Thrombosis were observed in 2 cases, decidual 138 arteriopathy was found in 3 cases. Fetal vascular malperfusion was observed in 7 patients, 139 only one of whom had gestational diabetes. Inflammatory disorders were found in 3 cases: 2 140 cases of villitis and one case of intervillitis, in all of which TORCH (Toxoplasmosis, Rubella, 141 CMV and Herpes virus) screening was negative. IUFD was related to cord anomaly in 4 142 cases: cord thrombosis in 3 cases, and tight loops in one case.

143 All the placentas of the 9 APL positive patients (definite and "non-criteria" APS) were 144 examined: all presented vascular disorders, which associated hypotrophy (constant) with 145 decidual arteriopathy in one case, infarcts in 8/9 cases, retroplacental hematoma in 2 cases, 146 and thrombi in two cases. In one patient was noted the co-existence of fetal vascular 147 malperfusion. 


\section{Results of the consultation}

151 The main causes of IUFD are reported in Table 1. Etiological categories were extracted from 152 the CODAC classification ${ }^{9}: 6$ cases issued from maternal causes, including the 5 definite 153 APS patients plus one patient whose IUFD was secondary to severe pre-eclampsia. IUFD of 154 "non-criteria" $(n=4)$ and non-APS patients $(n=27)$ were ruled as having a placental cause. 155 IUFD resulted from placental disorders in 36/53 (68\%) patients: placental insufficiency in 33 $156(62 \%)$ cases (including one case of pre-eclampsia), and placental inflammatory disorders in 3 $157(6 \%)$ cases (Table 1). None of our patients had isolated gestational hypertension, renal 158 disease or connective tissue disease.

159 IUFD was caused by fetal anemia in one case which was classified as a fetal cause, by 160 Parvovirus B19 infection in one case, and by funicular pathology in 4 cases.

161 IUFD remained unexplained in $11 / 53(21 \%)$ cases, including all the patients whose placenta 162 was not examined.

164 Comparison between APS, "non-criteria" APS and non-APS patients

165 The 36 patients who had significant placental disorders were allocated to one of the following 166 groups according to their APS status: definite APS, "non-criteria" APS and non-APS (in which 167 the patient with pre-eclampsia was included as her placenta exhibited hypotrophia along with 168 massive infarct and retroplacental hematoma).

169 Only the three patients with known APS had VTE history. Comparisons between the three 170 groups revealed that antecedent of VTE $(p=0.001)$ and placental infarcts $(p=0.047)$ were 171 significantly associated with the definite APS group, whereas fetal vascular malperfusion or 172 inflammatory disorders (villitis/ intervillitis) were not. Patients with "non-criteria" APS were not 173 different from non-APS patients regarding VTE history or pathological findings. 
174 There were no differences in mothers' age, time of pregnancy termination, presence of 175 livedo, history of fetal loss, or placental hypotrophia, between the 3 groups.

176

\section{DISCUSSION}

17853 cases of IUFD were referred to an internist over the study period. In the meantime, 440 179 cases were registered in our center, meaning that internists were consulted in $12 \%$ of cases. 180 Placental disorders were over represented, as they accounted for 31 (58\%) of cases, 181 whereas Bukowski et al. showed that they are usually involved in only $23.6 \%$ of IUFD. ${ }^{4}$ 182 Moreover, no genetic causes were observed while infectious and fetal causes were rarely 183 found (one case of each), although Bukowski et al demonstrated that such etiologies are 184 involved in respectively $29.3,13.7$ and $12.9 \%$ of IUFD. This reveals the selection bias which 185 applied while referring the patients to our department: a thorough etiological assessment had 186 previously been conducted by the obstetrician, thus ruling out the most common causes such 187 as genetics, infections or fetal pathologies. Overall, $36 / 53(68 \%)$ patients were referred to 188 investigate IUFD due to inflammatory or vascular placental disorders, which demonstrates 189 the obstetricians' expectations concerning internists in this field.

190 IUFD remains unexplained in $21 \%$ of cases which is comparable to the literature ${ }^{41011}$. These 191 include the 4 patients whose placenta was not examined. This emphasizes the crucial 192 importance of performing placental pathological examinations.

193 In our study, as previously demonstrated, placental examination was highly contributive ${ }^{12}{ }^{13}$, 194 since significant histological lesions were noted in 40/49 (81\%) cases (including cord 195 abnormalities in 4 cases).

196 As for patients with placental abnormalities, only 5/36 (14\%) were found to have APS 197 meeting Sydney criteria. ${ }^{5}$ Unsurprisingly, history of thrombosis was significantly associated 198 with the diagnosis of definite APS $(p=0.001) .{ }^{14}$ Among histological patterns, placental infarcts 
were associated with APS ( $p=0.047)$, whereas other lesions such as fetal thrombosis or villitis were not: this is consistent with previous studies which showed that infarcts is the most common pathological feature encountered in patients with obstetrical APS. ${ }^{15}{ }^{16}$ These results emphasize the need for APL testing in patients presenting a VTE history or placental infarcts. Diagnosing obstetrical APS is essential since such patients may benefit from the association of aspirin and heparin, which increases the live birth rate for future pregnancies up to $70 \%{ }^{17}$ 18

"Non-criteria" APS was discussed in 4/36 (11\%) patients, because of intermittent LA positivity and low-titers aCL in one of them, and isolated anti-prothrombin positivity in the 3 others. In our study, "non-criteria" APS patients were not different from non-APS patients regarding clinical or pathological features. Notably, they showed neither a larger history of thrombosis, nor more placental infarcts. This finding does not support the relevance of an entity such as "non-criteria" APS. The best treatment regimen whose would benefit to patients with "non-criteria" APS for future pregnancies is still debated ${ }^{1920}$, although Mekinian et al recently showed that they may benefit from the same treatment as patients with definite definite APS. ${ }^{21}$

Above all, 27/36 (75\%) patients did not have APS although they exhibited significant placental lesions. Placental inflammatory disorders, including villitis and intervillitis were found in 3 of our patients (8\%). Their physiopathology remains unclear in most of cases ${ }^{22}$; nevertheless previous studies have shown that such lesions might not be associated to APS. ${ }^{1523-26}$

The final question is to find out how to manage the future pregnancies of the $24 / 36(67 \%)$ APL negative patients who presented an IUFD related to placental vascular disorders. Aspirin is often prescribed, sometimes associated to heparin by analogy with APS patients. Nevertheless, previous studies have failed to demonstrate the validity of such attitude so far. 
$224{ }^{27-29}$ This situation raises the need for studies aiming at determining the best treatment 225 options in non-APS patients presenting IUFD of placental vascular origin.

226

227 CONCLUSION

228 The investigation of IUFD requires close multi-disciplinary collaboration, in which the internist 229 should play a substantial role. APL testing is a major feature of IUFD exploration, particularly 230 in cases of maternal venous thromboembolism history or in cases of placental infarcts, as 231 both were significantly associated to APS. Notably, most IUFD were found to originate from 232 placental vascular disorders which were not related to APS: further studies are needed to 233 determine the underlying mechanisms, in order to define the best treatment for future 234 pregnancies.

235

236 Abbreviations used:

237 aCL : Anti Cardiolipin Antibodies

238 APL: Antiphospholipid antibodies

239 APS: Antiphospholipid Syndrome

$240 \quad$ B2-GPI: Anti $\beta 2$ Glycoprotein I Antibodies

241 CNGOF : Collège National des Gynécologues-Obstétriciens Français/ French National 242 College of Gynecologists and Obstetricians

243 IUFD: In Utero Feta Death

244 LA: Lupus Anticoagulant

245 LDA: Low-Dose Aspirin

246 LMWH: Low-Molecular-Weight Heparin

247 PE: Pre-Eclampsia 


\section{Page 11 of 17}

1

2

3

248 VTE: Venous Thrombo-Embolism

249

5

7

8

9

10

11

12

13

14

15

16

17

18

19

20

21

22

23

24

25

26

27

28

29

30

34

35

36

37

38

39

40

41

42

43

44

45

46

47

48

49

50

51

52

53

54

55

56

57

58

59

60 


\section{REFERENCES}

251 1. Huchon C, Deffieux X, Beucher G et al (2016) Pregnancy loss: French clinical practice 252 guidelines. Eur J Obstet Gynecol Reprod Biol 201:18-26

253 2. Alexander S, Zeitlin J (2016) Stillbirths and fetal deaths-Better definitions to monitor 254 practice and policy across countries. BJOG Int J Obstet Gynaecol. doi: 10.1111/1471$255 \quad 0528.14381$

256 3. Lawn JE, Blencowe $\mathrm{H}$, Waiswa $\mathrm{P}$ et al (2016) Stillbirths: rates, risk factors, and 257 acceleration towards 2030. Lancet Lond Engl 387:587-603

258 4. Stillbirth Collaborative Research Network Writing Group (2011) Causes of death among 259 stillbirths. JAMA 306:2459-2468

260 5. Miyakis S, Lockshin MD, Atsumi T et al (2006) International consensus statement on an 261 update of the classification criteria for definite antiphospholipid syndrome (APS). J 262 Thromb Haemost JTH 4:295-306

263 6. Rodríguez-García V, loannou Y, Fernández-Nebro A, Isenberg DA, Giles IP (2015) 264 Examining the prevalence of non-criteria anti-phospholipid antibodies in patients with 265 anti-phospholipid syndrome: a systematic review. Rheumatol Oxf Engl 54:2042-2050

266 7. Khamashta M, Taraborelli M, Sciascia S, Tincani A (2016) Antiphospholipid syndrome.

268

269

270
267 Best Pract Res Clin Rheumatol 30:133-148

8. Khong TY, Mooney EE, Ariel I et al (2016) Sampling and Definitions of Placental Lesions: Amsterdam Placental Workshop Group Consensus Statement. Arch Pathol Lab Med 140:698-713 
271 9. Frøen JF, Pinar H, Flenady V et al (2009) Causes of death and associated conditions 272 (Codac): a utilitarian approach to the classification of perinatal deaths. BMC Pregnancy $273 \quad$ Childbirth 9:22

274 10. Gardosi J, Kady SM, McGeown P, Francis A, Tonks A (2005) Classification of stillbirth by 275 relevant condition at death (ReCoDe): population based cohort study. BMJ 331:1113276 1117

277

11. Smith GCS, Fretts RC (2007) Stillbirth. Lancet Lond Engl 370:1715-1725

278

279

280

281

282

12. Ptacek I, Sebire NJ, Man JA, Brownbill P, Heazell AEP (2014) Systematic review of placental pathology reported in association with stillbirth. Placenta 35:552-562

13. Zanconato G, Piazzola E, Caloi E, lacovella C, Ruffo R, Franchi M (2007) Clinicopathological evaluation of 59 cases of fetal death. Arch Gynecol Obstet 276:619 623

283

14. Reynaud Q, Lega J-C, Mismetti P et al. (2014) Risk of venous and arterial thrombosis 284 according to type of antiphospholipid antibodies in adults without systemic lupus 285 erythematosus: a systematic review and meta-analysis. Autoimmun Rev 13:595-608

15. Viall CA, Chamley LW (2015) Histopathology in the placentae of women with 287 288 antiphospholipid antibodies: A systematic review of the literature. Autoimmun Rev $14: 446-471$

289

290

291

292

293
16. Stone S, Pijnenborg R, Vercruysse L et al (2006) The placental bed in pregnancies complicated by primary antiphospholipid syndrome. Placenta 27:457-467

17. Rai R, Cohen H, Dave M, Regan L (1997) Randomised controlled trial of aspirin and aspirin plus heparin in pregnant women with recurrent miscarriage associated with phospholipid antibodies (or antiphospholipid antibodies). BMJ 314:253-257 
294 18. Bouvier S, Cochery-Nouvellon E, Lavigne-Lissalde G et al (2014) Comparative 295 incidence of pregnancy outcomes in treated obstetric antiphospholipid syndrome: the $296 \quad$ NOH-APS observational study. Blood 123:404-413

297 19. Arachchillage DRJ, Machin SJ, Mackie IJ, Cohen H (2015) Diagnosis and management 298 of non-criteria obstetric antiphospholipid syndrome. Thromb Haemost 113:13-19

299

20. Ramires de Jesús G, Levy RA, Porter TF, Branch DW (2015) Limited evidence for 300 diagnosing and treating "non-criteria obstetric antiphospholipid syndrome." Thromb Haemost 114:651-652

302 303 304 305 306 307 308

309

310

311

312

313

314 315 316

21. Mekinian A, Bourrienne M-C, Carbillon L et al (2016) Non-conventional antiphospholipid antibodies in patients with clinical obstetrical APS: Prevalence and treatment efficacy in pregnancies. Semin Arthritis Rheum 46:232-237

22. Derricott H, Jones RL, Greenwood SL, Batra G, Evans MJ, Heazell AEP (2016) Characterizing Villitis of Unknown Etiology and Inflammation in Stillbirth. Am J Pathol $186: 952-961$

23. Van Horn JT, Craven C, Ward K, Branch DW, Silver RM (2004) Histologic features of placentas and abortion specimens from women with antiphospholipid and antiphospholipid-like syndromes. Placenta 25:642-648

24. Magid MS, Kaplan C, Sammaritano LR, Peterson M, Druzin ML, Lockshin MD (1998) Placental pathology in systemic lupus erythematosus: a prospective study. Am J Obstet Gynecol 179:226-234

25. Ogishima D, Matsumoto T, Nakamura Y, Yoshida K, Kuwabara Y (2000) Placental pathology in systemic lupus erythematosus with antiphospholipid antibodies. Pathol Int $50: 224-229$ 
1

2

3

4

5

6

7

8

9

10
317 26. Boog G (2008) Chronic villitis of unknown etiology. Eur J Obstet Gynecol Reprod Biol $318 \quad 136: 9-15$

319 27. Kaandorp SP, Goddijn M, van der Post JAM et al (2010) Aspirin plus heparin or aspirin 320 alone in women with recurrent miscarriage. N Engl J Med 362:1586-1596

321 322 complications: an update. Br J Haematol 168:619-638

323

324

325

326

327

328

329

330

331

332

333

334

335

336

28. Duffett L, Rodger M (2015) LMWH to prevent placenta-mediated pregnancy

29. Clark P, Walker ID, Langhorne P et al (2010) SPIN (Scottish Pregnancy Intervention) study: a multicenter, randomized controlled trial of low-molecular-weight heparin and low-dose aspirin in women with recurrent miscarriage. Blood 115:4162-4167

\section{Captions:}

Figure 1. Repartition of cases according to gestationnal age. 


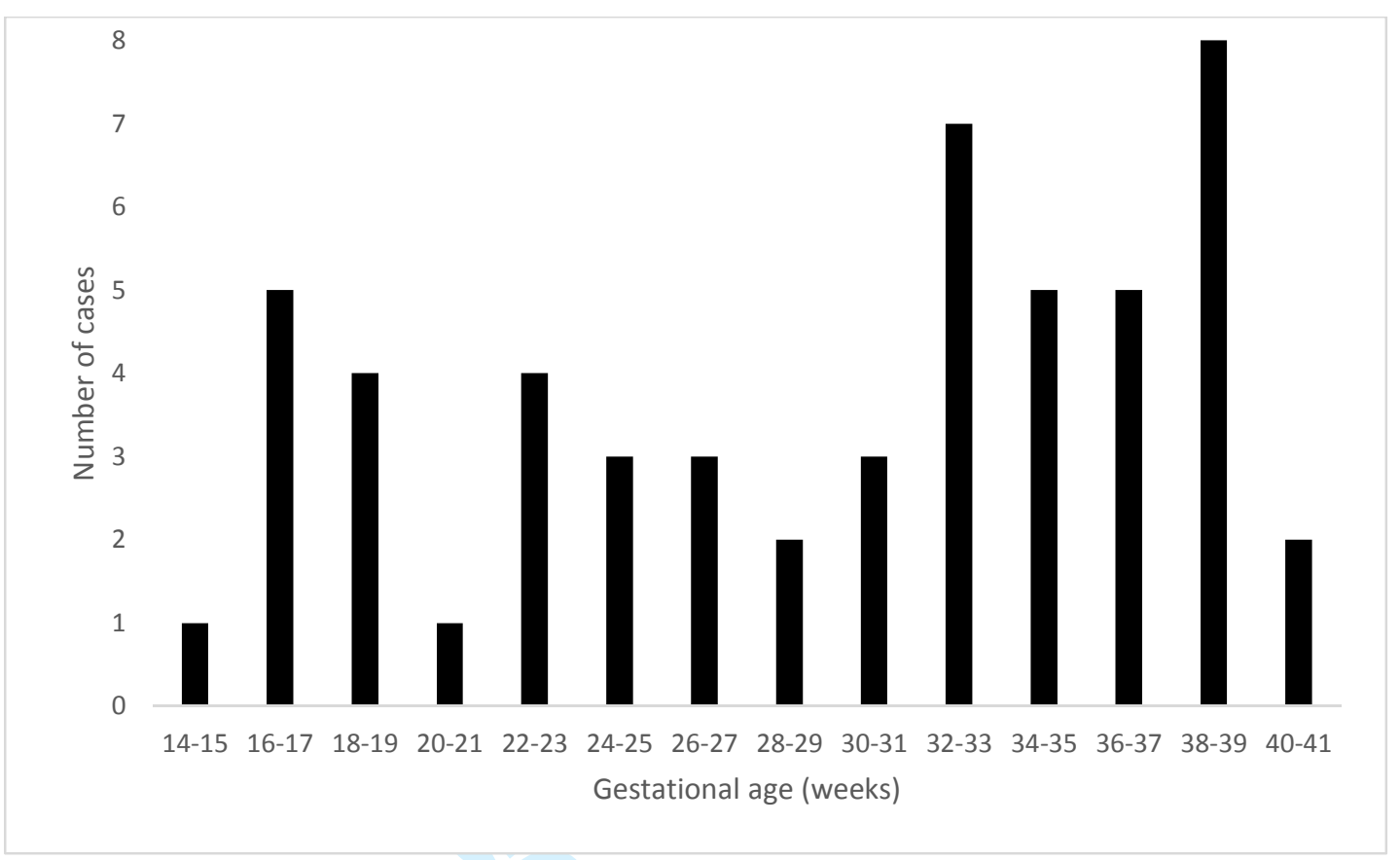

Figure 1. Distribution of cases according to gestationnal age. 
1

2

3

4

5

6

7

8

9

10

11

12

13

14

15

16

17

18

19

20

21

22

23

24

25

26

27

28

29

30

31

32

33

34

35

36

37

38

39

40

41

42

43

44

45

46

47

48

49

50

51

52

53

54

55

56

57

58

59

60

Table 1. Main cause of In Utero Fetal Death, determined through expert agreement.

Abnormal placentas $\left[\begin{array}{lll}\hline \text { Main cause of IUFD } & \text { N } & \% \\ \text { Placental } & \text { Total: } 53 & \\ (27 \text { PVD, 3 PID }) & 30 & 56.6 \\ \text { Maternal disease } & 6 & 11.3 \\ \text { (5 proven APS, 1 PE) } & & \\ & & \\ \text { Cord conditions } & 4 & 7.5 \\ \text { Infection } & 1 & 1.9 \\ \text { Fetal } & 1 & 1.9 \\ \text { Intrapartum or } & 0 & 0 \\ \text { obstetric complication } & & \\ \text { Congenital/ genetic } & 0 & 0 \\ \text { Unknown } & 11 & 20.8 \\ \text { Total } & 53 & 100 \\ \hline\end{array}\right.$

Abbreviations: IUFD: In Utero Fetal Doss; PVD: Placental Vascular Disorders; PID: Placental inflammatory Disorders; APS: Antiphospholipid Syndrome; PE: Pre-Eclampsia. 